\title{
Breves biografías ficticias. Posibilidad de un género literario lectorial
}

\author{
Curta biografia de ficção. Possibilidade de um gênero literário do leitor \\ Short fictional biography. Posibility of a reader's literary genre \\ Rafael Andugar Sousa \\ Universidad de Barcelona, Barcelona, España \\ $\diamond$
}

Resumen: En este artículo se parte de los presupuestos teóricos postulados por el científico J. M. Schaeffer para crear un nuevo género literario basándose en la comparación que el lector puede establecer de obras literarias diversas que incluso pueden no pertenecer a la misma tradición. El objeto de interés es la existencia de relatos y cuentos breves que narran la biografía inventada de personajes históricos reales o ficticios por diversos autores. Para explorar los límites del género es necesario conocer en profundidad el campo de la biografía y sus relaciones con la escritura literaria y ficcional además de las relaciones con la historiografía.

Palabras clave: Literatura comparada; Género literario; Biografía; Autoficción

Resumo: Neste artigo, baseia-se nos pressupostos teóricos postulados pelo cientista J. M. Schaeffer para criar um novo gênero literário baseado na comparação que o leitor pode estabelecer de diversas obras literárias que nem sequer pertencem à mesma tradição. $\mathrm{O}$ objeto de interesse é a existência de histórias curtas e histórias curtas que narram a biografia inventada de personagens históricos reais ou ficcionais por diferentes autores. Para explorar os limites do gênero, é necessário conhecer em profundidade o campo da biografia e suas relações com a escrita literária e ficcional, bem como as relações com a historiografia.

Palavras-chave: Literatura comparada; Gênero literário; Biografia; Autoficção

\begin{abstract}
In this article, we begin from the theoretical implications vislumbrated by J. M. Schaeffer with the porpose to create a new literary genre based in the task of the reader to compare diverse literary works which maybe don't belong to the same tradition. The object of our interest is the existence of tales and narrations of biographies which are invented by an author interested in real historical characters (or even also invented). To explore the limits of the genre is necessary to know deeply the field of biografphy and the relations with literary writing and the relations with historiographical discourse too.
\end{abstract}

Keywords: Comparative literature; Literary genre; Biography; Self-fiction

"Ya no existe biblioteca, a partir de ahora, cada cual leerá a su aire."

(Maurice Blanchot, "La última palabra”) 


\section{Estado de la cuestión y propuesta de lectura}

Durante la lectura de una serie de libros surgió una intuición crítica de que detrás de todos ellos se escondía una conexión en común. Existía cierta similitud en algunos rasgos que compartían pese a las marcadas diferencias ya fueran de contenido o formales. Gracias al recurso del teórico de los géneros literarios francés Jean-Marie Schaeffer la cuestión se pudo desarrollar más extensamente. Se trata de la posibilidad de existencia de un género literario que han cultivado distintos escritores en sus obras y que, a pesar del reconocimiento de muchos de ellos de la adhesión a ésta tradición literaria, puedan llegar a existir otras obras no adscritas que presenten también semejanzas.

Lo hemos denominado "breves biografías ficticias" y más adelante se tratará de reconstruir el modelo virtual del que participan una serie de obras testigos como por ejemplo "Vidas imaginarias" de Schwob, "Historia universal de la infamia" de Borges, "La sinagoga de los iconoclastas" de Rodolfo Wilcock, "La literatura nazi en América" de Bolaño, "Los emigrados" de Sebald, "La enciclopedia de los muertos" de Danilo Kiš o "Los nuestros" de Dovlatov, entre otros.

En el proceso de investigación apareció una tesis doctoral de Cristian Crusat (que más tarde publicó en el libro "Vidas de vidas. Una historia no académica de la biografía. Entre Marcel Schwob y la tradición hispanoamericana del siglo XX") que trataba extensamente el género que denomina "vidas imaginarias". De gran utilidad para la redacción de éste artículo, Crusat detalla todas las acometidas de otros investigadores para delimitar el género, del cual todos ellos coinciden al intuir su existencia. Nuestra propuesta pretende ser una apostilla final que deje abierta la cuestión para futuras reincorporaciones dentro del género de obras perdidas en ésta historia de la literatura trazada por Crusat y no limitar así la serie tradicional de obras. Nuestra hipótesis es que Crusat y los demás investigadores han partido de una intuición lectorial pero han querido olvidar su posición de lectores y centrarse en la reconstrucción de una tradición genérica basada en las influencias hipertextuales entre los distintos autores. Para comprender las diferencias metodológicas entre la investigación de Crusat y la nuestra es necesario antes que nada recordar las distinciones pertinentes que traza en su teoría de los géneros literarios Schaeffer.

La diferencia entre las lógicas genéricas y las clases según la relación de modulación de los textos literarios es la clave. Por un lado existe la clase genealógica y por otro la analógica. La clase genealógica es la que estaría en juego en el estudio de Crusat y otros investigadores ya que se trata de encontrar las relaciones hipertextuales entre los textos y detallar cómo funciona la tradición literaria que ha permitido la aparición del género. Los autores han partido del modelo anterior para imitarlo, parodiarlo, mezclarse o alejarse de él (SCHAEFFER, 2006, p. 118-119). El autor es uno de los centros de interés, por ejemplo si en algún momento ha declarado que le gusta Schwob o que su obra se basa en las "Vidas imaginarias" el investigador del género de clase genealógica lo recopila, por esa razón el estudio de Crusat está repleto de citas de los autores. Estas citas suelen hacer hincapié en los mecanismos que han puesto en marcha los autores en el proceso de creación. Crusat propone las "Vidas imaginarias" de Schwob como iniciador de la tradición que se traspasaría a Argentina gracias a la imitación de Alfonso Reyes y la posterior recreación de Borges que sería después el siguiente escalón de influencia que dejaría una huella textual en el género. Es así como estudia las relaciones hipertextuales pero no solamente se detiene en el siglo XX sino que trata de trazar de dónde surge el modelo genérico. Evidentemente Schwob no es totalmente original y le obliga a retroceder buscando otros autores anteriores que han posibilitado el surgimiento como Diógenes, Aubrey, Boswell y De Qincey. Todos ellos se convierten en precursores de Schwob y la tradición genérica de las "biografías imaginarias".

Por otro lado, ante la reconstrucción genérica de clase genealógica que realiza Crusat proponemos un acercamiento al género tratándolo como si fuera de clase analógica ya que

por el contrario, los géneros construidos sobre la simple relación de semejanza tienen un estatus lectorial (incluso aunque puedan solaparse parcialmente con relaciones de genericidad autorial, dado el carácter múltiple de las lógicas de semejanza) (SCHAEFFER, p. 120-121).

La clase analógica surge de la intuición del propio lector, ante una serie de lecturas establece semejanzas de manera indeterminada construyendo un modelo virtual e ideal del cual todas las obras son variaciones en mayor o menor medida. El modelo ideal no existiría materialmente, pero las obras compartirían rasgos con él y por esa razón se asemejarían entre ellas. Para poder proseguir es necesario describir y tipificar el modelo virtual del cual las obras que pertenecerían al género serían puras variaciones (SCHAEFFER, p. 123).

Hipotéticamente, el estudio de Crusat parte también de una intuición lectora con un modelo ideal en mente y por esa razón trata de buscarlo en obras testigo como la de Borges o la de Schwob que autorialmente tienen peso en la tradición. Pero la intención de éste artículo no es 
la de reafirmar la tradición y la institución literaria, las cuales se benefician del estudio genealógico, sino la de hacer uso del comparatismo y privilegiar más la figura del lector que la del autor. Además, el estudio en exclusiva genealógico de este género implica dejar fuera toda obra que a pesar de ser también similar no pertenezca a la tradición. El estudio desde la posición del lector posibilita la incorporación de obras de tradiciones alejadas en el tiempo y el espacio que por casualidad se asemejen. Así, es enriquecedor el conocimiento de la existencia de una constelación de obras dispares pero con fundamentos similares de cualquier época y lugar. En todo caso, es necesario remarcar que metodológicamente el estudio desde la posición del lector no tiene necesidad del estudio genealógico como explica Schaeffer:

Las clases analógicas hacen abstracción de la variabilidad de los contextos porque son principio de juego lectoriales y porque la cuestión de una eventual tensión entre genericidades autoriales y lectoriales no puede producirse. Incluso cuando una clase analógica se superpone parcialmente a una clase de convenciones tradicionales o a convenciones reguladoras (como sucede muy a menudo), esta superposición se neutraliza metodológicamente, ya que el mismo principio de formación de la clase analógica pone entre paréntesis la genericidad autorial (p. 125).

Por último, la descripción del género será realizada en contraste con el género genealógico estudiado por Crusat y analizando las obras testigo seleccionadas tratando de ponerlas en relación. Para ello, se problematizará la posición que implica el género en el nivel de tensión teórica entre ficción y biografía y como aparece explicitado en algunas obras, detenerse en la representación final de la muerte de los biografiados puede ser una manera ejemplificadora. Además se detallarán rasgos semejantes como la parodia de las compilaciones.

\section{Las obras testigo y el modelo ideal}

Para describir el género de las "breves biografías ficticias" desde la posición lectorial es necesaria

la construcción de un tipo textual ideal: este tipo, construido generalmente a partir de ciertas obras consideradas como 'ejemplares' del género, es a menudo tratado como una definición de comprensión del género, mientras que, en realidad, se trata de una ficción metatextual. La definición de un género de este tipo sólo podría ser definida como "estadística», en el sentido de que sólo puede medirse la curva de las desviaciones que las obras reales trazan respecto a ese patrón metatextual que es el ejemplar genérico ideal (p. 122).
Es decir, al tratarse de un género basado en las analogías que establece el lector su definición se basa en una ficción en sí, no existe una obra que contenga todas las características. Para Crusat, en cambio, las "Vidas imaginarias" de Schwob sería el modelo definitivo, meta de todas las tentativas precedentes y origen de todas las reconstrucciones posteriores. Privilegia la sección de un modelo único para demostrar las transformaciones respecto a éste. La metodología del estudio analógico debe basarse en la multiplicidad modélica y es necesario poner atención en las variaciones. Por lo tanto, se ha de seleccionar una gran cantidad de obras testimoniales que permitan entre todas ellas establecer un tipo ideal con el que poder establecer una definición que sea capaz de permitir la entrada y salida de otras obras que no se correspondan del todo con el modelo virtual.

Por lo que respecta al nombre del género, Crusat elige "vidas imaginarias" ya que Schwob es quien crea el modelo de la tradición de la cual tiene intención investigar. Explica como el término "vida" es más apropiado que "biografía" ya que tiene "mayor tradición", más "polisemia" y porque confunde "historia y leyenda" (CRUSAT, 2015, p. 108). Sin embargo, la biografía no le interesa ya que es más "metodológica" y se encuentra subyugada a "los documentos y los textos históricos" impidiendo una libertad creadora al autor. La elección del nombre "biografías ficticias" parece más adecuado para el estudio comparativo y no basado en la tradición que viene de Schwob ya que en muchas obras la tensión con la historiografía, la memoria histórica y el recurso al documento cobra una relevancia más primordial y distinta que en la obra de Schwob. La diferencia entre imaginario y ficcional también dota de un sentido más amplio al género ya que se tiene en cuenta así una dimensión de la realidad textual. Se trata de la puesta en cuestión de la verdad y la mentira que se da en la literatura posmoderna. La ficción biográfica tiene en cierto sentido características similares a la auto-ficción salvando la distancia de que no es una escritura del "yo" sino del "él", es decir, no es del sujeto sino del objeto.

Paul de Man en "La autobiografía como desfiguración" polemiza con el hecho de que la autobiografía dependa de un referente y le atribuye cierto carácter ficcional, algo que se puede también trasponer al terreno de la biografía. De Man se pregunta:

¿no podemos sugerir, (...) que tal vez el proyecto autobiográfico determina la vida, y que lo que el escritor hace está, de hecho, gobernado por los requisitos técnicos del autorretrato, y está, por lo tanto, determinado, en todos sus aspectos, por los recursos de su medio? Y, puesto que la mimesis que se asume como operante en la autobiografía es un modo de figuración entre otros, $¿$ es el referente quien determina la figura o al revés? ¿No será que la ilusión referencial proviene de la estructura de la figura, es decir, que no hay clara 
y simplemente un referente en absoluto, sino algo similar a una ficción, la cual, sin embargo, adquiere a su vez cierto grado de productividad referencial? (DE MAN, 1991, p. 113).

Con estas palabras De Man postula que los límites entre la (auto)biografía y la ficción son muy débiles (precisamente Lejeune hablará de que solo es posible la creencia en el carácter verídico de la biografía mediante el pacto de lectura que establece el lector con el autor) ya que el referente no existe en el lenguaje porque es la narración la que lo construye mediante los signos haciendo alusión sin llegar a ser, procedimiento que se lleva tanto en la ficción más especulativa como en los documentos biográficos que tratan de imitar los acontecimientos reales. Asimismo, Genette en "Fiction narrative, factual narrative" compara narratológicamente el modo de narrar ficcional y el basado en hechos llegando a la conclusión de que no tienen diferencias (1993, p. 83). La ficción es una simulación de los hechos según Searle (57) pero la narración de los hechos también es un simulacro en sí.

Las "breves biografías ficticias" se compondrían de breves narraciones o fragmentos que detallarían acontecimientos de carácter biográfico ficcional en la vida de personajes reales o imaginarios. Este tipo de obras tienen intención de problematizar el estatuto ontológico de las narraciones biográficas que se basan en documentos y acontecimientos reales. De diversas maneras, las obras entran en colisión con la historia objetiva desde la literatura y remarcan el carácter textual de ambas narraciones al igual que la imposibilidad de un conocimiento objetivo de la historia como explica Hayden White en "La posmodernidad y las ansiedades textuales”. Según White, existiría una ideología detrás del objetivismo que pretende separar el estatuto ontológico de las narraciones históricas de las ficticias.

La "biografía ficcional" fue ya advertida de manera problemática por Dorrit Cohn en "Vies fictionelles, vies historiques: limites et cas limites" cuando al construir una tabla en la que oponía el dominio de la Historia al de la Ficción ya fuera en narraciones en primera o tercera persona se encontraba con el caso:

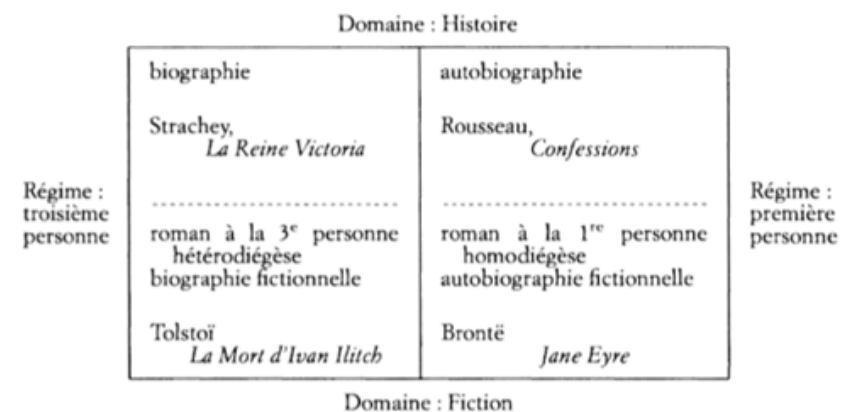

Fig. 1. Dorrit Cohn pone el ejemplo de "La Muerte de Ivan Ilitch" (1997, p. 25).
Las "breves biografías ficticias" se situarían en la frontera difuminada de la tabla (Dorrit Cohn explica que está difuminada ya que no existe realmente tal oposición al igual que Paul de Man había ya advertido "la distinción entre ficción y autobiografía no es una polaridad o/o, sino que es indecible (p. 114)."

La biografía ficcional la ejemplifica con "La Muerte de Ivan Ilitch" de Tolstoi citando el estudio de B. H. Smith "On the Margins of Discourse" donde explica ella:

The Death of Ivan Illyitch is not a biography of a fictional character, but rather a fictive biography ... Tolstoy is, if you like, pretending to be writing a biography while actually fabricating one (COHN, p. 27, cita de SMITH, p. 29-30).

Pero Dorrit Cohn dice no estar de acuerdo con Smith ya que la obra de Tolstoi no pretende ser biográfica a causa de la extensa y dramática muerte de Iván. En una biografía sería inverosímil que se pudieran conocer tantos detalles de la conciencia del biografiado en el instante de su muerte (p.27-28). El ejemplo de Tolstoi termina acabando más en un margen cercano a la simple novela que el límite del caso de estudio de las "breves biografías ficticias". Frente la extensión que parece alejar a la literatura de la biografía, la brevedad y la concisión parecen ser rasgos que dan más verosimilitud al género de las biografías ficticias y por esa razón se vuelve inherente.

La característica de la brevedad es relevante ya que ayuda a concretar porque en las formas extensas también encontramos biografías ficcionales de muchos tipos como el caso de Augusto Monterroso y "Lo demás es silencio (La vida y la obra de Eduardo Torres)", el cual se asemeja al procedimiento de Bolaño de mezclar la vida de escritores con la obra pero de manera más extensa, o el caso más alejado de la tradición occidental como es el japonés Junichiro Tanizaki y "La vida enmascarada del señor Musashi", el cual se sirve de fuentes imaginarias para reconstruir la biografía ficticia de un samurái. Además, las biografías ficticias se vería con un problema insalvable si se considerasen de manera extensa porque la novela o la biografía terminarían por desequilibrar el género en sí. Por un lado la novela decimonónica como la "Bildungsroman" se acercaría de manera vertiginosa al modelo ficticio biográfico, obras como "Grandes esperanzas" de Dickens podrían cumplir gran parte de los requisitos. Y por otro lado, una biografía basada en hechos reales y con una labor de reconstrucción documentada como "María Antonieta" de Stefan Zweig siempre tendrá un punto de dramatismo, propio de la narración biográfica, que le otorgaría valor ficcional en menor o mayor medida.

Crusat también destaca la brevedad como rasgo fundamental ya que Schwob "pretende rescatar algunos hechos recónditos de cada personaje, de ahí que lo 
anecdótico y lo mínimo cobre una importancia esencial" (p.204) y la tradición hispanoamericana que le sigue (Alfonso Reyes, Borges, Bioy Casares, Wilcock, Bolaño) cumplen el requisito para "resaltar una serie de hechos concretos que individualizarían al personaje" (p.242).

Otras características que compartirían esta tradición según Crusat serían las "descripciones en las que predominan tanto la sordidez como los elementos visionarios y de cariz onírico", "la excentricidad" de los personajes y el "carácter meta-literario" (p. 242-243). Así es, en "Vidas imaginarias" de Schwob encontramos descripciones tan dispares al final de las vidas de los casos de "Empédocles, supuesto dios" y "Katherine la randera, muchacha de amoríos" ya que Empédocles muere de manera sublime cuando

un esclavo contó asustado que había visto un dardo rojo surcando las tinieblas hacia el cumbre del Etna. Los fieles ascendieron las estériles cuestas de la montaña a la triste luz del alba. El cráter del volcán vomitaba un haz de llamas. Sobre el poroso brocal de lava que circundaba el abismo ardiente se halló una sandalia de bronce torcida por el fuego (SCHWOB, 1982, p. 21).

Y Katherine en cambio degollada después de rebajarse a lo más sórdido:

Katherine acabó harta de vivir enclaustrada en un cuarto cuadrado y huyó a los caminos. Ya nunca más fue parisiense ni randera, sino que imitó a los que merodean por los alrededores de las ciudades francesas o se sientan en las piedras de los cementerios a la espera de proporcionar placer a los que pasan. Muchachas que no tienen más nombre que el que se adecua a su apariencia, y Katherine recibió el nombre de Hocico (p. 116-117).

Los personajes de Schwob también son excéntricos de la misma manera que los personajes inventores de artilugios extraños y portadores de ideas bizarras contenidos en las páginas de "La sinagoga de los iconoclastas" de Wilcock y los escritores filonazis de Bolaño, entre otros.

Es el caso de Tabucchi por ejemplo, ya que alejándose de la tradición escribió un ensayo sobre las "Autobiografías ajenas" haciendo alusión a las epístolas ficticias que relatan la vida de personajes inventados de "Se está haciendo cada vez más tarde" y que un lector le dijo que una de ellas "ha contado en síntesis esa autobiografía que yo nunca fui capaz de escribir" (p.99). La problemática linda con el terreno teórico de la autoficción ya que si el lector pudo reconocerse en una figuración ficticia azarosa es a causa de las propiedad de la narración literaria de construir referentes tan verosímiles como los reales. En la obra de Tabucchi está el caso dentro de "Dama de Porto Pim" del breve relato de "Antero de Quental. Una vida" que se asemeja más a las "breves biografías ficticias". En ésta la muerte final de Antero adquiere una relevancia especial. Tabucchi en el ensayo de "Autobiografías ajenas" explica la importancia del "epitafio" en la narración de una vida, la importancia de la inscripción de las vivencias o los acontecimientos biográficos, y la escritura que termina siendo definitiva como la muerte misma (TABUCCHI, 2006, p. 107). La muerte es uno de los temas que la mayoría de las "breves biografías ficticias" tratan y es de gran importancia ya que el modo en como esté tratada puede determinar el grado de verosimilitud de la ficción. Dorrit Cohn había descartado como biografía el caso de Tolstoi ya que la dramatización de la muerte de manera extensa era impropia del arte biográfico y continúa explicando:

Aucun moment de la vie - si l'on peut dire - ne souligne de façon plus dramatique que la mort et l'agonie la différence de nature entre biographie et fiction, entre la contrainte qui pèse sur le biographe et la liberté du romancier. Car la fiction est capable de raconter une expérience qui ne peut être évoquée sous aucune forme par le discours 'naturel'. C'est peut-être pourquoi les romanciers - les grands réalistes tout comme les grands antiréalistes - nous offrent perpétuellement la mimesis d'une conscience qui se meurt. En dehors des nombreux exemples qu'on trouve dans Tolstoï, on pensera aux importantes scènes d'agonie focalisées dans Un cœur simple, La Mort à Venise, La Mort d'Artemio Cruz, La Mort de Virgile ${ }^{1}$. Le dernier de ces ouvrages est particulièrement probant, puisque le protagoniste du roman de Hermann Broch est un personnage aussi historique que la Victoria de Strachey. Cette oeuvre de plus de cinq cents pages porte entièrement sur les dernières vingt-quatre heures de la vie du poète romain, et constitue probablement le plus long exercice en style indirect libre de la littérature mondiale. Aucun lecteur ne pourrait jamais prendre une seule de ces pages pour de la biographie historique, en dépit de la liste des sources historiques donnée en appendice (28).

Es por ello que un análisis comparativo de las escenas finales y las muertes ${ }^{2}$ de los personajes de las "breves biografías ficticias" sería de especial interés.

Otra característica propia del género sería la aparición en recopilaciones enciclopédicas que agruparían

\footnotetext{
1 De las obras que menciona se podría llegar a hacer un análisis comparativo e incluso hablar de un género analógico también, en este caso la lectora sería Dorrit Cohn

2 "Morts imaginaires" de Michel Schneider es otra obra que podría ser estudiada ya que, como Dosse explica, es continuadora de la tradición de Schwob ya que "evoca mediante 'tanatografias' la muerte de escritores, sus últimas palabras a partir de los datos de que dispone, tales como los testimonios sobre sus últimos momentos de agonía" (DOSSE, 2007, p.57), además de que Schneider entiende que "toda biografía es una novela", rompiendo con la dicotomía.
} 
las diversas biografías inventadas. Los compendios de biografías ficticias terminan resaltando la importancia de la individualidad y la multiplicidad de existencias diferentes en el mundo. Dorrit Cohn explica que tradicionalmente la historiografía ha tratado la humanidad en plural sin tener en cuenta la individualidad de la que se ha ocupado más la ficción literaria:

L'histoire traite de l'humanité au pluriel plutôt qu'au singulier, et porte sur des événements et des changements affectant des sociétés entières plutôt que l'existence des seuls individus. C'est pourquoi la biographie est souvent considérée comme un genre historique mineur, et même par certains comme 'une forme simple d'historiographie'. Dans la fiction, par contre, des intrigues centrées sur la vie d'individus isolés et plus ou moins singuliers structurent les modes génériques dominants appelés en français 'roman de l'individu', et en allemand Figurenroman. Tous les romans de ce type ne suivent pas ce que Bakhtine appelle le chronotope du temps biographique. En fait, l'une des distinctions possibles entre récit de fiction et récit historique est que le premier peut faire apparaître l'ensemble d'une vie comme un tout unifié dans un espace de temps narratif très bref, réduit à une seule journée dans des romans comme Ulysse ou Mrs. Dalloway (COHN, 1997, p. 24).

Las "breves biografías ficticias" tratarían de dislocar ésta concepción al dar una importancia superior e histórica a un individuo desde la ficción. Sigue la propuesta de Emerson en su ensayo History: "private experience flashes a light on what great bodies of men have done, and the crises of his life refer to national crises" (2001, p. 106), es decir, la importancia de las vidas privadas acaban por terminar afectando a la historia nacional. Desde la ficción esta concepción adquiriría una vuelta de tuerca más.

\section{Variaciones genéricas: compendios de familiares fallecidos}

Una variación genérica importante es la del testimonio de la vida de un familiar o amigo cercano desaparecido. Este tipo de relatos se encuentran en las obras siguientes: "Los emigrados" de Sebald, "Los nuestros" de Dovlátov, "Vidas minúsculas" de Michon y "La Enciclopedia de los muertos" de Kiš. También los poemas de "Spoon River Anthology" de Edgar Lee Masters responden a necesidades parecidas ya que el poeta recrea la vida ficcional de todos los difuntos de un pueblo imaginario. Se cumplen dos de los rasgos que presentan la mayoría de "breves biografías ficticias": el afán de antologizar y el testimonio de las muertes de sus personajes. A pesar de no estar narrada de manera prosaica y presentar un testimonio externo, estos versos breves también son similares a muchas de las propuestas que atestiguan la existencia de las biografías ficticias.

En "Los emigrados" de Sebald, el narrador recopila el recuerdo que se tiene de cuatro judíos exiliados allegados a él. Se tratan de un antiguo casero y amigo Henry Selwyn, su maestro de primaria Paul Bereyter, su tío abuelo Ambros Adelwarth y un pintor también amigo Max Aurach. El maestro Paul Bereyter se quita la vida "tendiéndose en la vía del tren a las afueras de S.” (SEBALD, 2015, p. 35) y justo antes, en el inicio del relato, Sebald deja una fotografía del lugar exacto:

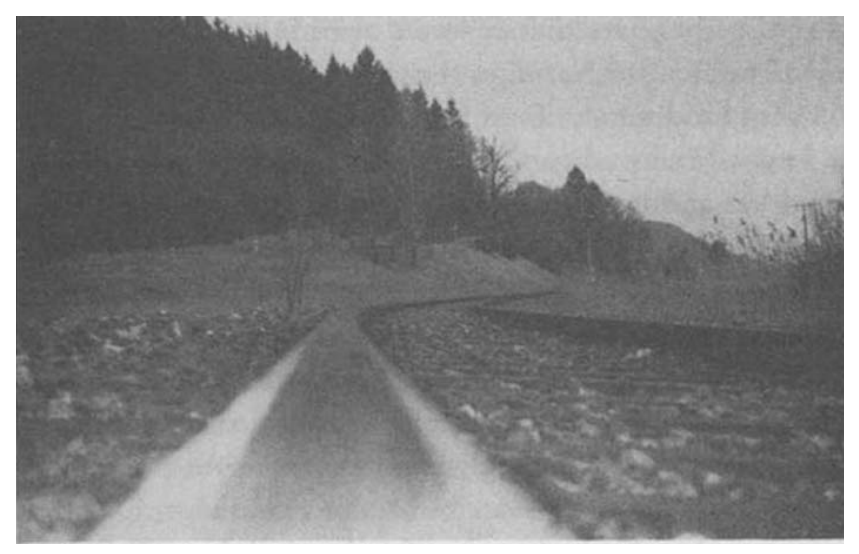

Fig. 2. "allí donde la línea férrea sale del bosquecillo de sauces describiendo una gran curva para ganar el campo abierto" (SEBALD, p. 35).

Puede parecer que el biógrafo conoce con exactitud el lugar de la muerte de Paul Bereyter y por esa razón adjunta una prueba fotográfica para documentarlo. La narración que trata de acercarse todo lo posible a los hechos verídicos y a la realidad incluso mediante la incorporación de fotografías que van pausando el relato, se acaba alejando totalmente y adquiere un lirismo simbólico y dramático cuando se comienza a especular sobre el instante final de la muerte. Primero el narrador constata que desata su imaginación al respecto sobre los hechos que desconoce de la vida privada de Paul:

Por esta razón he intentado, con mucho retraso, acercarme a él, he tratado de imaginar cómo vivió en la espaciosa vivienda de la planta superior de la antigua casa Lerchenmüller que había antes en el lugar que ocupa hoy el bloque de pisos...

A continuación enumera una serie de situaciones en las que lo ve actuando de manera totalmente imaginada:

Lo veía tumbado en la galería cubierta de tablones -su dormitorio de verano, con el rostro expuesto al paso continuo de los ejércitos estelares; lo veía en invierno patinando a solas sobre el hielo del estanque piscícola 
de Moosbach; y lo veía tendido en la vía del tren. En mi imaginación se había quitado las gafas y las había puesto a un lado sobre el balasto. Los brillantes carriles de acero, las traviesas, el bosquecillo de pinos junto a la cuesta de Altstadt y el arco de montañas que le eran tan familiar se habían desdibujado ante sus ojos miopes, hasta desvanecerse en el crepúsculo. Al final, cuando se acercaba el golpeteo del tren, todo lo que veía era de color gris oscuro, pero en medio, con punzante nitidez, quedaba la imagen persistente de los picos nevados del Kratzer, del Trettach y del Himmelsschrofen (p. 37).

En este fragmento podemos ver resumida una de las propuestas de las "breves biografías ficticias", se trata de imitar el género biográfico y los documentos verídicos que hacen acopio de registrar la historia y la realidad de la vida desde la literatura. La ficción termina invadiendo el relato ya que es la única herramienta para recuperar una imagen del pasado inalcanzable como el instante de la muerte de un suicida solitario. La teoría psicoanalítica respaldaría la hipotética posibilidad de recuperar la memoria borrada o pérdida del inconsciente haciendo uso de un lenguaje literario en el que las metáforas y las metonimias jugarían un papel importante como el que desempeñan en la cadena de significante del inconsciente humano. Según Lacan, el inconsciente estaría estructurado de manera similar al lenguaje (LACAN, 1977, p. 68-69), por esa razón la verosimilitud simbólica de la escena final de Sebald justifica el procedimiento literario. Paul únicamente ve los montes porque es miope, al igual que elige morir en las vías de un tren porque "el ferrocarril tenía para Paul un significado profundo. Es probable que siempre le pareciera que llevaba a la muerte" (p.71) ya que su mujer había sido deportada en un tren a un campo de concentración donde murió. A nivel literario, tiene sentido la correspondencia simbólica y por esa razón dota de sentido a la realidad que simula.

Michon en "Vidas minúsculas" cuenta la biografía de amigos de la infancia y familiares a medio camino entre realidad y ficción. En la "Vida de André Dufourneau" ocurre lo mismo que en Sebald, el narrador comienza a imaginar aquello de lo que no tiene conocimiento y surge una retórica de la incertidumbre. Si reconstruye algunos datos a partir de unas cartas, confiesa que "creo leer lo que jamás leí" (MICHON, 2009, p. 21) y

también pienso en aquello de lo que no hablaba: algún secreto insignificante nunca revelado -no por pudor, sin duda, sino, lo que es equivalente, porque el material lingüístico del que disponía era demasiado reducido para exponer lo esencial, y su orgullo demasiado inflexible para permitir que lo esencial se encarnara en palabras humildemente aproximadas (p.21).

Aquí el lenguaje es valorado como incapaz de transmitir según qué experiencias. El narrador tiene que hacer uso de la invención porque no recuerda nada ya que

el héroe y su biógrafo se encuentran debajo del castaño, pero como siempre ocurre, la entrevista es un fiasco: el biógrafo está en la cuna y no conservará ningún recuerdo del héroe (p.21).

Como el narrador aun no tenía consciencia es "testigo" pero no ve "nada" (p.22) y por eso solo puede fabular: "me imagino que Élise..." (p.22). En Michon hay mucha más fabulación que en Sebald ya que en la propia narración se contienen todas estas marcas textuales de reconocimiento de la propia creación de la ficción. La muerte de André Dufourneau es desconocida por el biógrafo ya que la supone: "aquel café y aquella carta fueron las últimas señales de la vida de Dufourneau. Les siguió un definitivo silencio, que ni quiero ni puedo interpretar más que por la muerte" (p. 23) y a continuación viene un listado de hipótesis ficticias al estilo de la narrativa de Bolaño: "en cuanto a la forma en que lo alcanzó la Madrastra, las conjeturas pueden ser infinitas; pienso en un Land Rover volteado en un surco de laterita color de sangre (...)" (p.23). La ficción adquiere un estatuto de superioridad frente a la realidad más verosímil cuando el narrador se decanta por "la hipótesis más novelesca $-\mathrm{y}$, eso me gustaría creer, la más probableme fue sugerida por mi abuela (...)" (p. 24). Al final del relato, el narrador se pregunta por la superioridad de las ficciones frente a los acontecimientos históricos reales ya que son más poderosos y permanecen en la memoria: André Dufourneau "no dejó huella más que en la ficción que elaboró una vieja campesina difunta" (p.26).

Dovlátov en "Los nuestros" sigue un procedimiento parecido pero distinto a la vez, se trata de una novela compuesta de distintos relatos breves en los que explica sus recuerdos de distintos familiares suyos y la vida en la Unión Soviética o la vida de emigrado en Estados Unidos. Su propuesta es contar desde la intimidad familiar y la individualidad el contexto histórico. En el capítulo VI, por ver un episodio, comienza diciendo "la biografía de Arón, marido de mi tía, retrata con toda fidelidad la historia de nuestro Estado" (DOVLÁTOV, 2000, p. 69) y narra sus vaivenes poniendo énfasis en las contradicciones en las que caía continuamente el hombre: por un lado creía fervientemente en el comunismo adorando a Stalin y por otro lado era un disidente ya que por ejemplo "en la cabecera de su cama colgaba un pequeño retrato de Solzhenitsyn. Cuando venían invitados, lo descolgaba..." (p.79). Existe un correlato entre la idea que expone Dovlátov de "como ya he dicho, la biografía de mi tío refleja la historia de nuestro estado... De nuestro querido y horrible país..." (p. 79) y aquello que expresa reiteradas veces Emerson en su ensayo "History": 
If the whole of history is in one man it is all to be explained from individual experience. There is a relation between the hours of our life and the centuries of time (EMERSON, 2001, p. 105).

Es la idea de que la biografía de una persona equivale a contar la historia de su época, de los tiempos en los que vivió: "All history becomes subjetive in other words, there is properly no History; only Biography” (p.108). Es todo lo contrario a como tradicionalmente se había concebido la historia y la biografía según Dorrit Cohn (p.24). Las "breves biografías ficticias" suelen acercarse a la historia a contrapelo, permitiendo al lector reconstruir el contexto mediante el individuo y rescatando del olvido fragmentos de la totalidad inabarcable. En el caso de Dovlátov, Arón se convierte en alegoría de las contradicciones de la propia URSS, y en el de Sebald, el maestro es una víctima de la persecución de los judíos por los nazis.

Bolaño en "La parte de los crímenes" de "2666" construye un archivo simulado que sirve de memorial de las mujeres asesinadas en el feminicidio de Ciudad Juárez. Se encuentran cientos de necrológicas de mujeres de las cuales solo se tiene poca información. Witthaus escribe que Bolaño construye una biografía negativa a partir de "las actas de la policía, en unos datos forenses, con currículos tanto precarios como fragmentarios, cuyos elementos parecen algo aleatorios" (WITTHAUS, 2015, p.68). Son "breves biografías ficticias" también ya que pese a que todas las muertas que narra son trasuntos ficcionalizados de la realidad, inventa e imagina más allá de la información que los archivos reales propician:

Una semana después, cuando ya agosto llegaba a su fin, fue encontrado en la carretera Santa Teresa-Cananea el cuerpo de Jacqueline Ríos, de veinticinco años, empleada en una tienda de perfumería de la colonia Madero. Iba vestida con pantalones vaqueros y blusa gris perla. Tenis blancos y ropa interior negra. Había muerto por disparos de arma de fuego en el tórax y el abdomen. Compartía casa con una amiga en la calle Bulgaria, en la colonia Madero, y ambas soñaban con irse a vivir algún día a California. En su habitación, que compartía con su amiga, se encontraron recortes de actrices y actores de Hollywood y fotos de distintos lugares del mundo. Primero queríamos irnos a vivir a California, encontrar trabajos decentes y bien pagados, y después, ya establecidas, visitar el mundo en nuestras vacaciones, dijo su amiga. Ambas estudiaban inglés en una academia privada de la colonia Madero. El caso quedó sin aclarar (BOLAÑO, p. 579).

El estado de la muerta es el resumen de su pasado y de lo que es en el presente ya que no podrá vivir más, por ello Witthaus habla de "biografía negativa". Las palabras de la amiga y los proyectos de futuro de Jacqueline Ríos quedan marcados como la vida que no pudo ser. Los individuos también marcan la historia para Bolaño.

La culminación de la obsesión por el documento y el archivo, la confección de listas y del relato pormenorizado de todos los detalles y acontecimientos biográficos se parodia en "La Enciclopedia de los muertos (toda una vida)" de Kiš. Es un relato en el que la narradora explica su llegada a una biblioteca sueca en la que encuentra de noche y misteriosamente "la enciclopedia de los muertos" una suerte de "libro de arena" borgiano redactado por una secta y que contiene las biografías de todas las personas que no figuran en "ninguna otra enciclopedia" (KIŠ, 2002, p.48) y a partir del año 1789 (p.49). A medida que describe el funcionamiento de la enciclopedia se va relatando la biografía ficticia del padre de la narradora. Ella decide copiar y resumir su biografía para tener una prueba tangible pero únicamente consigue transcribir "nombres, lugares, fechas" (p. 46) ya que la enciclopedia lo abarca absolutamente todo: "la multitud de detalles que constituyen la vida de un hombre" y "está escrito todo. Todo.” (p.46). Durante páginas Kiš consigna de manera meta-literaria una gran multitud de datos y acontecimientos biográficos ficticios. La enciclopedia es capaz de evocar con su lenguaje la realidad, hacerla presente y dejar atrás la imitación sustituyéndola, hecho totalmente fantástico:

su estilo, esta increíble amalgama de concisión enciclopédica y de elocuencia bíblica. Por ejemplo, la sucinta anotación siguiente, que consta en mi cuaderno tal y como la había apuntado, se extiende allí a lo largo de varios párrafos, con tal densidad narrativa que en el espíritu del lector aparece por un momento, como por arte de magia, el paisaje resplandeciente del sol, el rápido desfile de las imágenes (p.49).

Ésta obra de Kiš se convierte en la culminación de las "breves biografías ficticias" ya que participa en el género pero a la vez lo parodia y subvierte desde la metaliteratura, reflexionando sobre la propia intención de la biografía y la imposibilidad de su objeto. La moraleja del relato fantástico sería que la vida de un ser humano no puede ser consignada en un libro:

No voy a referiros aquí lo que recuerdo de la forma en que allí se consigna, se describe, todo lo que sigue -el día y el desarrollo de la petición de mano, la boda a la antigua usanza, donde se gasta de todo a espuertas, todo el pintoresco folclore que forma parte de esta vida-, pues me parecería insuficiente y fragmentario con relación al original (p.56).

La narración propia es consciente de su "insuficiencia" y "fragmentariedad" respecto al "original" que es la "Enciclopedia de los muertos", pero la enciclopedia es 
un libro fantástico (e inexistente) así que en verdad se está remitiendo a la imposibilidad de registrar la totalidad de la vida real.

Finalmente, si Dorrit Cohn afirmaba que la biografía tradicionalmente se consideraba un género historiográfico menor al tratar solo la vida de un individuo y no la de todos, Kiš en el relato participa de la idea de Emerson de no hay Historia sin Biografía proclamando la multiplicidad de la diversidad y su carácter específico:

Porque nunca se repite nada en la historia de los seres humanos $-\mathrm{y}$ creo que en ello radica el mensaje esencial de los autores de la Enciclopedia...-, todo lo que a primera vista aparece igual apenas es similar; cada hombre es un astro aparte, todo ocurre siempre y nunca, todo se repite hasta el infinito y de forma irrepetible. (Por eso, los autores de la Enciclopedia de los muertos, este grandioso monumento a la desemejanza, insisten sobre lo particular, cada ser humano es para ellos sagrado) (p. 57)

Y:

La historia es para el Libro de los muertos la suma de los destinos humanos, un conjunto de acontecimientos efímeros. Por esta razón está reseñada cada actividad, cada pensamiento, cada soplo creador, cada cota inscrita en el registro, cada pala de barro, cada movimiento que haya desplazado un ladrillo de los muros derrumbados (p. 63).

Todos estos relatos acaban coincidiendo en la importancia del testimonio y la conservación en la memoria colectiva de los individuos porque son ellos los que constituyen en su conjunto (pero sobre todo en su especificidad) la Historia. La imposibilidad del conocimiento absoluto y total de la experiencia de los individuos ajenos implica que el único medio posible para aproximarse verosímilmente es la ficción y la fabulación.

\section{Conclusión}

Dada la limitación de la extensión del artículo, es imposible continuar profundizando en la multiplicidad de las obras y la diversidad de relatos que comprenden. Sin embargo, se ha llevado a cabo una selección de ejemplos paradigmáticos y una aproximación a varías características similares relevantes que tienen en común las obras. Además, en cuanto a la tradición hispanoamericana ya existe el estudio de Crusat que se detiene en profundidad aunque con una metodología distinta. El acercamiento desde la posición lectorial permite aumentar los ejemplos encontrados y buscar más características que nutran este estudio en otras tradiciones distintas.

En resumen, el modelo ideal que se podría llegar a vislumbrar estaría a medio camino entre la biografía historiográfica seria y la ficción como una suerte de autoficción en el terreno de la narración en tercera persona. Rasgos que acotarían para aproximarse a una definición serían la brevedad y la posibilidad de la pertinencia del relato biográfico a un compendio. La función sería parodiar las consignas del saber enciclopédico o la memoria de la vida de individuos para que no sea olvidada por la historia. Cobra así especial relevancia la ficción y la imaginación de lo oculto por la historia y la vida de los individuos al igual que el tratamiento de la historia de la humanidad de manera singular y no plural, siguiendo la concepción de Emerson pero con la libertad creativa de la ficción.

\section{Referencias}

BAJTÍN, Mijaíl. Teoría y estética de la novela. Taurus, Alfaguara: Madrid. 1989.

BOLAÑO, Roberto. La literatura nazi en América. Planeta: Barcelona, 1998.

BOLAÑO, Roberto. 2666. Anagrama: Barcelona, 2012.

BORGES, Jorge Luis. Historia universal de la infamia. Madrid: Diario El País, 2002.

COHN, Dorrit. Vies fictionnelles, vies historiques: limites et cas limites. Littérature, n. 105, p. 24-48, 1997.

CRUSAT, Cristian. Vidas de vidas. Una historia no académica de la biografía. Entre Marcel Schwob y la tradición hispanoamericana del siglo XX. Madrid: Páginas de Espuma, 2015.

DICKENS, Charles. Grandes esperanzas. Alba: Barcelona, 2012.

DE MAN, Paul. La autobiografía como desfiguración. Suplemento Anthropos, n. 29, p. 113-118, 1991.

DOSSE, François. El arte de la biografía: entre historia y ficción. México: Universidad Iberoamericana, 2007.

DOSSE, François. La apuesta biográfica. Escribir una vida. València: Publicacions de la Universitat de València, 2007.

EMERSON, Ralph Waldo. Emerson's Prose and Poetry. New York: A Norton Critical Edition, 2001.

KIŠ, Danilo. La Enciclopedia de los muertos. Barcelona: El Aleph, 2002.

KIŠ, Danilo. Lección de anatomía. Barcelona: Acantilado, 2013.

KIŠ, Danilo. Una tumba para Boris Davidovich. Barcelona: Acantilado, 2015.

LACAN, Jacques. Las formaciones del inconsciente. Buenos Aires: Nueva visión, 1977.

LEE MASTERS, Edgar. Spoon River Anthology. Londres: Hesperus Press, 2005.

LEJEUNE, Philippe. El pacto autobiográfico y otros estudios. Madrid: Endymion, 1994.

GENETTE, Gérard. Fiction and diction. New York: Cornell University Press, 1993. 
MICHON, Pierre. Vidas minúsculas. Barcelona: Anagrama, 2009.

MONTERROSO, Augusto. Cuentos, fábulas y Lo demás es silencio. Madrid: Diario El País, 2003.

REYES, Alfonso. Retratos reales e imaginarios. Barcelona: Bruguera, 1984.

SCHAEFFER, Jean-Marie. ¿Qué es un género literario? Madrid: Akal, 2006.

SCHWOB, Marcel. Vidas imaginarias. Barcelona: Bruguera, 1982.

SEBALD, Winfried Georg. Los emigrados. Barcelona: Anagrama, 2015.

SPANG, Kurt. Géneros literarios. Madrid: Síntesis, 1996.

TABUCCHI, Antonio. Autobiografías ajenas. Poéticas a posteriori. Barcelona: Anagrama, 2006.
TANIZAKI, Junichiro. La vida enmascarada del señor Musashi. Barcelona: Edhasa, 1989.

WHITE, Hayden. La ficción de la narrativa. Buenos Aires: Eterna Cadencia, 2011.

WILCOCK, Juan Rodolfo. La sinagoga de los iconoclastas. Barcelona: Anagrama, 1981.

WITTHAUS, Jan-Henrik. Biografía negativa en "La parte de los crímenes" de Roberto Bolaño. In: HENNIGFELD, Ursula (Ed.). Roberto Bolaño. Violencia, escritura, vida. Madrid: Iberoamericana, 2015.

Recebido: 08/10/2017

Aprovado: 04/02/2018

Contato:

Rafael Andugar Sousa <rafael_andugar94@hotmail.es> ORCID: <https://orcid.org/0000-0003-0359-7888> 